\title{
Reversibly Physisorbed and Chemisorbed Water on Carboxylic Salt Surfaces Under Atmospheric Conditions
}

\author{
Xiangrui Kong,* Dimitri Castarède, Anthony Boucly, Luca Artiglia, Markus Ammann,
} Thorsten Bartels-Rausch, Erik S. Thomson, and Jan B. C. Pettersson*

Cite This: J. Phys. Chem. C 2020, 124, 5263-5269

Read Online

\section{ACCESS | Llll Metrics \& More | 回 Article Recommendations | (s) Supporting Information}

ABSTRACT: The particle-gas interface in aerosol systems is of essential importance because it is here that many key atmospheric processes occur. In this study, we employ ambient pressure X-ray photoelectron spectroscopy (APXPS) to investigate the surface properties and processes of an atmospherically relevant carboxylic salt, sodium acetate, at subdeliquescence conditions. From the depth profiles of the elemental ratios of sodium, oxygen, and carbon, we find that after deliquescence-efflorescence cycles the salt surface is sodium-depleted. The mechanism of the observed depletion is proposed to be (i) the formation of neutral acetic acid in the solution due to the nature of the basic salt; (ii) the selective surface enhancement of neutral molecules under aqueous condition; and (iii) a hypothetical kinetic barrier to rehomogenization due to spatial separation and special local conditions on the surface, resulting in varied local surface composition. When the relative humidity gradually increases and approaches the deliquescence point, both reversible water uptake and reversible surface dissociation are confirmed by near-edge X-ray adsorption fine structure (NEXAFS)

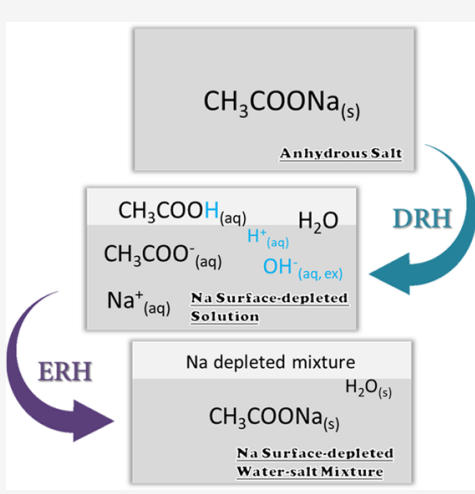
spectroscopy at the oxygen K-edge and sodium K-edge, respectively. The solvation of sodium requires a higher relative humidity than needed for water adsorption, which suggests that water molecules are taken up by the surface, but the solvation of the salt surface begins only when sufficient water molecules are present, to facilitate the process. The sodium-depleted surface requires additional adsorbed water to affect and dissolve the sodium ions in deeper regions.

\section{INTRODUCTION}

Particle-gas interfaces are of essential importance in aerosol systems, and they directly determine many atmospheric processes, ${ }^{1,2}$ such as surface-catalyzed chemistry, ${ }^{3,4}$ halogen chemistry, ${ }^{5}$ trace gas uptake, ${ }^{6}$ new particle formation, ${ }^{7}$ ozone depletion, ${ }^{8}$ and heterogeneous ice nucleation. ${ }^{9}$ Interfacial processes often start with the adsorption of gas molecules or clusters on particulate surfaces. The adsorbed molecules may then be incorporated into bulk materials, and those molecules may directly influence particle properties. ${ }^{10}$ Affected bulk properties, like viscosity, ${ }^{11}$ chemical reactivity, ${ }^{12}$ and crystalline structure, ${ }^{13}$ may in turn affect further uptake capacity, thereby acting as feedbacks. Thus, to correctly understand aerosol interfaces and to quantify atmospheric processes, one needs to precisely describe surface properties at the given environmental conditions.

Traditionally, particle-gas equilibria are well defined by classical thermodynamic theories like the Köhler theory, which describes the equilibrium water vapor pressure over soluble particles as a function of water activity and particle size. However, these simplified concepts become uncertain when considering microscopic systems like molecular adsorption on the outermost layer of particles. For example, airborne sea salt particles, which are the second most abundant aerosol particle species, ${ }^{14}$ deliquesce (transition from solid particles to aqueous solution droplets) by absorbing water vapor and completely dissolve at a critical relative humidity $(\mathrm{RH})$, which is defined to be the deliquescence relative humidity (DRH). ${ }^{15}$ Likewise, they effloresce (recrystallize into salt) at an efflorescence relative humidity (ERH). The traditional conception of these transitions is captured by an understanding of bulk phase equilibrium and neglects surface effects. However, surfacesensitive studies reveal that salt surfaces begin to adsorb water at $\mathrm{RH}$ well below the bulk phase transition, ${ }^{16-22}$ leading to a predeliquescence solvation of the surface. ${ }^{23-25}$ Moreover, these initial surface changes can be critical for atmospheric processes due to their direct relevance for heterogeneous atmospheric chemistry. ${ }^{14}$

The presence of water layers on salt surfaces is important to understand as they directly determine the surface properties and it is apparent that adsorption and even solvation begin at RHs well below the bulk DRHs. A clear understanding of when adsorption is sufficient to initiate surface solvation, and a quantification of the transition between these regimes, remains

Received: January 13, 2020

Published: February 5, 2020 
lacking. Existing experimental methods are usually insufficient to address the question of when physisorption succumbs to solvation. For example, FTIR measurements of $\mathrm{O}-\mathrm{H}$ stretching ${ }^{21,22}$ are mainly sensitive to initial water adsorption. Other techniques such as e-AFM ${ }^{19}$ or ETEM $^{20}$ are sensitive to morphological changes but may not detect chemical changes. Many spectroscopic methods lack surface-specific sensitivity, which hinders the detection of surface changes prior to bulk transformations. Thus, although observations agree on the existence of adsorbed water below the $\mathrm{DRH}$, it remains unclear when the water quantities are sufficient to dissolve the salts in a manner that results in stable aqueous solution layers. To date, only a few studies have attempted to discuss dissociation with a predeliquescence regime. ${ }^{20,21}$

Carboxylic acids are prevalent in the troposphere and are involved in many important chemical reactions. ${ }^{26}$ Acetic acid is one abundant carboxylic acid that is widely emitted from biomass burning, ${ }^{27}$ motor exhaust, ${ }^{28}$ and biogenic sources, ${ }^{29}$ and is an important product of oxidation of anthropogenic and biogenic volatile organic compounds (VOCs). Once released, the acid can react with inorganic salts like $\mathrm{NaCl}$ and form sodium acetate (and $\mathrm{HCl}$ ), which is found in internally mixed sea salts and organic particles. ${ }^{30}$ Typically, the more volatile $\mathrm{HCl}$ escapes to the gas phase, resulting in chlorine-depleted sea salt aerosols. ${ }^{31}$ Thus, given the abundant source material, carboxylic salts are also widespread within the atmosphere. However, detailed studies of the phase behavior of carboxylic salts at relevant atmospheric conditions are still largely lacking. The observed temperature $(T)$-dependent sodium acetate $\mathrm{DRH}$ is between 39 and $42 \%$ at $20^{\circ} \mathrm{C}$ and slightly higher (43$44 \%)$ at $25{ }^{\circ} \mathrm{C},{ }^{32,33}$ with $\operatorname{ERH}(T) \approx \mathrm{DRH}(T)-7 \% .^{33,34}$ In addition, after crystallization at sub-ERH $(\mathrm{RH}<10 \%)$ conditions, water still coexists with the salt as a mixture with a salt-to-water ratio of $2: 1 .^{33}$

In this study, X-ray photoelectron spectroscopy (XPS) is employed to investigate the sodium acetate $(\mathrm{NaAc}$, chemical formula $\mathrm{CH}_{3} \mathrm{COONa}$ ) surface phase state and structure. In XPS, soft X-ray photons irradiate sample materials and the emitted electrons that result are collected to determine the composition and state of the sample. It is a highly surfacesensitive and chemically selective method that is used to characterize the chemical composition, oxidation state, and degree of dissociation, and with a tunable photon source it can be used to construct depth profiles of such information. The inelastic mean free path (IMFP) of emitted electrons results in an XPS surface sensitivity that, to a certain degree, overlaps with the presumed thicknesses of liquid-like layers on salt surfaces. Ambient pressure XPS (APXPS) is a technique that has been developed ${ }^{35-39}$ to directly probe surfaces under atmospheric relevant vapor pressure conditions. For example, a pioneering APXPS study investigated the premelting of ice ( $T$ $\left.>-39^{\circ} \mathrm{C}\right) .{ }^{40}$ More recently, APXPS was used to investigate the existence of molecular $\mathrm{HCl}$ versus ionic $\mathrm{Cl}^{-}$at gas-ice interfaces at $-20{ }^{\circ} \mathrm{C}^{41}$ Carboxylic acids, ${ }^{42-44}$ ketones, ${ }^{45}$ alcohols, ${ }^{46}$ and nitrates ${ }^{47}$ have also been studied for their adsorption onto, dissociation on, and diffusion into ice, including surface-disordering effects. In addition, solid-tosolution phase transitions of salt at various RHs have also been studied with APXPS, for example, $\mathrm{KBr}$ - and $\mathrm{KI}$ - water binary systems ${ }^{48}$ and the $\mathrm{NaCl}$-water system. ${ }^{49}$ In the former studies, upon deliquescence, Ghosal et al. found an immediate surface enhancement of halide ions in the aqueous system. ${ }^{48}$ The implementation of APXPS applied here is innovative because of its focus on the surface-specific phase state. In particular, we investigate $\mathrm{NaAc}$ surfaces at subdeliquescence conditions, but over a range of increasing $\mathrm{RH}$ as the DRH is approached. Thus, we seek to distinguish between physisorbed water, which can reversibly desorb, and water layers, which result in the dissociation and solvation of the salt species.

\section{MATERIALS AND METHODS}

The APXPS experiments described here were performed at the $\mathrm{X} 07 \mathrm{DB}$ in situ spectroscopy beamline of the Swiss Light Source (SLS) at the Paul Scherrer Institute (PSI), using the solid-gas interface end station. ${ }^{36}$ Prior to and between measurements, the experimental cell was held under highvacuum conditions $\left(6 \times 10^{-8} \mathrm{mbar}\right.$ base pressure $)$ to avoid contamination from the ambient environment. The $\mathrm{NaAc}$ sample (anhydrous, ReagentPlus, $\geq 99.0 \%$, Sigma-Aldrich) was dissolved in anhydrous methanol and deposited onto the sample holder by drop-casting. The sample holder was subsequently warmed to $60{ }^{\circ} \mathrm{C}$ to accelerate the methanol evaporation, resulting in the formation of the anhydrous salt, after which the sample was transferred into the vacuum chamber. Once mounted in the experimental chamber, a complete deliquescence-efflorescence cycle was performed by increasing the environmental cell $\mathrm{RH}$ to $46 \%$ (>DRH), followed by decreasing the $\mathrm{RH}$ to $3 \%$ to remove the majority of the adsorbed water. Mixtures of anhydrous and hydrated samples were observed to form after this cycle, but can be distinguished as either anhydrous-dominated or hydrateddominated (see the hydrated sample in Figure S3), where the anhydrous-dominated samples are the focus of this study. The phase cycling also helped to ensure a more homogeneous sample distribution on the holder. Water vapor was dosed from a temperature-controlled water reservoir $\left(T=15{ }^{\circ} \mathrm{C}\right)$ via a stainless steel capillary of $800 \mu \mathrm{m}$ inner diameter. The water source (Fluka TraceSelect Ultra; Water ACS reagent) was degassed using three freeze-pump-thaw cycles, and the resulting in-chamber vapor pressure of between 0.68 and 0.74 mbar corresponds to the saturation vapor pressure of ice at approximately $-24{ }^{\circ} \mathrm{C}$. During the experiments, the water vapor pressure was kept constant while the sample temperature was varied to change the RH. The $3 \% \mathrm{RH}$ value was set using a stable $20{ }^{\circ} \mathrm{C}$ sample temperature and a water vapor pressure of $0.71 \mathrm{mbar}$. At $\mathrm{RH}=36.1 \%$, the temperature was $-14{ }^{\circ} \mathrm{C}$, while at $\mathrm{RH}=34.6 \%$ it was $-13.5{ }^{\circ} \mathrm{C}$. A summary of the experimental $\mathrm{RH}$ and temperature can be found in Table S1.

The photon source of the X07DB beamline is a bending magnet that provides photons with energies between 250 and $1500 \mathrm{eV}$. The beam size at the sample surface was approximately $0.2 \times 0.2 \mathrm{~mm}^{2}$. The XPS survey spectrum was acquired using a $1000 \mathrm{eV}$ photon energy, with the carbon $1 \mathrm{~s}$ peaks measured at $1070 \mathrm{eV}$. For depth profiling, seven kinetic energies were selected-380, 480, 580, 680, 780, 880, and 980 $\mathrm{eV}$. The measured XPS spectra were fitted with Gaussian functions and a linear background. To obtain correct elemental ratios, $\mathrm{CO}$ gas measurements with these depth profile photon energies were conducted, and the results were used to normalize the photon flux, photoionization cross sections, and analyzer transmission for $\mathrm{C} / \mathrm{O}$ ratios. Good agreements were found between literature photoionization cross sections and measured photoionization cross sections. Based on this, the $\mathrm{Na}$ intensities were normalized by literature photoionization cross sections and measured photon flux and analyzer transmission. Partial electron yield near-edge X-ray 
absorption fine structure (NEXAFS) spectroscopy is extremely sensitive to the local coordination environment of an emitter; thus, the sodium K-edge and oxygen K-edge NEXAFS experiments were performed to probe the water adsorption and changes in the local chemical environment. The NEXAFS and XPS experiments were performed, in turn, on the same samples during the beamtime.

\section{RESULTS AND DISCUSSION}

3.1. Sample Characterization. Figure la shows a widerange XPS scan acquired with a $1000 \mathrm{eV}$ photon excitation
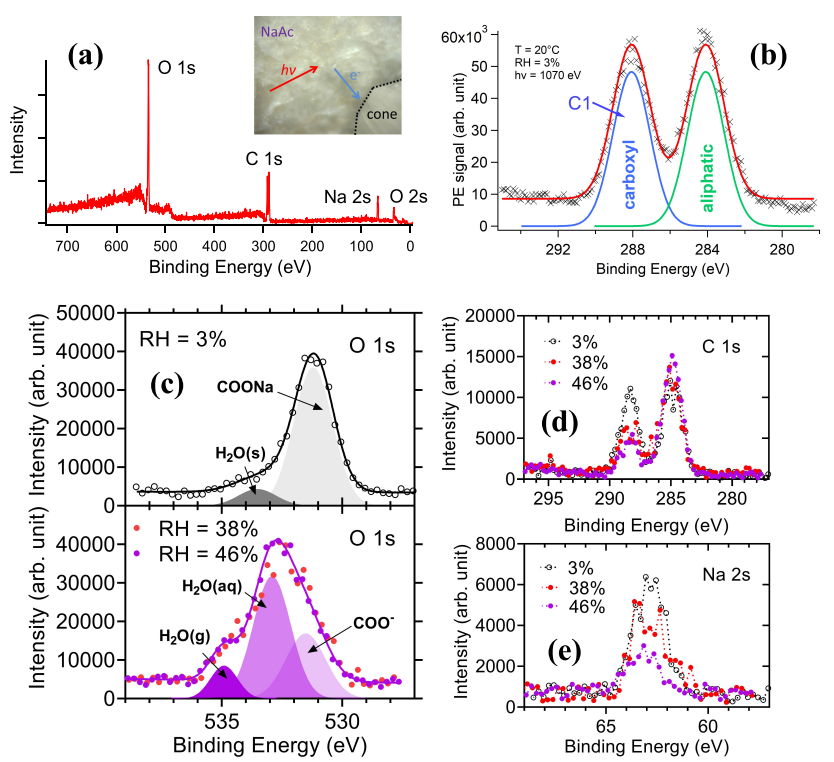

Figure 1. (a) XPS spectra with distinct peaks as a function of electron binding energy identified from 0 to $745 \mathrm{eV}$, measured from a $1000 \mathrm{eV}$ photon excitation energy. An image of the sample surface inside the environmental cell during measurements, with the analyzer cone seen in the lower-right corner, is the inset. (b) High-resolution spectra of the $\mathrm{C}$ 1s peaks fitted with Gaussian functions representing the carboxyl and aliphatic components, respectively. The carboxyl group is identified as $\mathrm{C} 1$ for later reference. The excitation photon energy for the high-resolution scan is $1070 \mathrm{eV}$. In both (a) and (b), RH $=3 \%$ and $T=20{ }^{\circ} \mathrm{C}$. A fitted $\mathrm{C} 1 \mathrm{~s}$ spectrum at $\mathrm{RH}=46 \% \mathrm{can}$ be found in Figure S1. In (c) O 1s, (d) C 1s, and (e) Na 2s, photoelectron spectral peaks at three different RHs $(3,38$, and $46 \%)$ are presented and are aligned by the aliphatic carbon $\mathrm{C} 1 \mathrm{~s}$. The photon excitation energy is $1000 \mathrm{eV}$. In (c), $\mathrm{H}_{2} \mathrm{O}(\mathrm{s})$ refers to the $\mathrm{H}_{2} \mathrm{O}$ in the hydrate salt or the adsorbed water remaining after dehydration, $\mathrm{H}_{2} \mathrm{O}(\mathrm{aq})$ is water in solution, and $\mathrm{H}_{2} \mathrm{O}(\mathrm{g})$ is water vapor. In the lower panel, due to the similarity of the two spectra, only the $\mathrm{RH}=46 \%$ data is fitted.

energy. All and only the expected elements from the $\mathrm{NaAc}$ (oxygen 1s, carbon 1s, sodium 1s, and oxygen 2s) were identified in the scan, indicating that the sample was free from contaminants at $\mathrm{RH}=3 \%$. In Figure $1 \mathrm{~b}$, the high-resolution $\mathrm{C}$ 1s core level photoelectron (PE) spectrum is plotted and decomposed into the carboxylic and aliphatic carbon components. ${ }^{43}$ The two components were almost identical in area and separated by $4.0 \mathrm{eV}$, in agreement with a previous study of an acetic acid solution. ${ }^{50}$ The PE spectra around the $\mathrm{O} 1 \mathrm{~s}, \mathrm{Na} 2 \mathrm{~s}$, and $\mathrm{C} 1 \mathrm{~s}$ peaks at $\mathrm{RH}=3 \%\left(20^{\circ} \mathrm{C}\right), 38 \%(-15.5$ $\left.{ }^{\circ} \mathrm{C}\right)$, and $46 \%\left(-18{ }^{\circ} \mathrm{C}\right)$ are plotted in Figure $1 \mathrm{c}-\mathrm{e}$, respectively, and they are all aligned with aliphatic $\mathrm{C} 1 \mathrm{~s}$ at $284.8 \mathrm{eV}$. At $\mathrm{RH}=3 \%$, the $\mathrm{O} 1 \mathrm{~s}$ spectrum is dominated by the oxygen of the acetate ions. In carboxylic acids, the oxygens appear as two peaks separated by $1.5 \mathrm{eV} .{ }^{51}$ However, in our $\mathrm{NaAc}$ sample these two peaks are not resolved, possibly due to one of them being dominant in the ionic crystal. We have therefore fitted this as one single, sufficiently broad component to the $\mathrm{O} 1 \mathrm{~s}$ peaks. Already at $\mathrm{RH}=38 \%\left(-15.5^{\circ} \mathrm{C}\right.$, $\mathrm{DRH}$ is $\leq$ $38 \%)$ the solid-to-liquid phase transition has occurred, which is reflected in the changes of the $\mathrm{O} 1 \mathrm{~s}$ region and intensity changes of $\mathrm{C} 1 \mathrm{~s}$ and $\mathrm{Na} 2 \mathrm{~s}$. Upon deliquescence, the $\mathrm{O} 1 \mathrm{~s}$ peak changes shape entirely due to the appearance of the dominating condensed phase water feature at $532.9 \mathrm{eV}^{43}$ The total area increases by $23 \%$ at $\mathrm{RH}=38 \%$ and by $29 \%$ at $\mathrm{RH}=46 \%$, respectively. Due to dissociation, the COONa component at $531.2 \mathrm{eV}$ is replaced by the $\mathrm{COO}^{-}$component at a slightly higher binding energy at $531.5 \mathrm{eV}$. Note that even at $\mathrm{RH}=3 \%$ there is a small component at $533.5 \mathrm{eV}$, which is either the $\mathrm{H}_{2} \mathrm{O}$ of the hydrate salt or the adsorbed water remaining after dehydration. At the two higher RHs, there is an additional $\mathrm{O} 1 \mathrm{~s}$ component at $534.9 \mathrm{eV}$, which is most likely associated with gas-phase water vapor. The reason that the gasphase water became visible at high RHs might be the increased working distance when the salt surface turns to solution or enhanced local vapor pressure over the aqueous surface. The observed decreased intensities of the $\mathrm{C} 1 \mathrm{~s}$ and $\mathrm{Na} 2 \mathrm{~s}$ at $\mathrm{RH}=$ $38 \%$ and $46 \%$ can be attributed to increased attenuation and dilution by the condensed phase water. Conversely, the relative increase of the $\mathrm{C} 1 \mathrm{~s}$ peak at $\sim 285 \mathrm{eV}$ with increasing $\mathrm{RH}$ is likely due to carbon contamination (see Figure S1).

3.2. Depth Profile. To analyze the surface composition as a function of depth, depth profiles (DPs) of the elemental ratios with increasing photon energy were derived. The depth information is based on the dependence of the electron inelastic free mean path (IMFP) on the electron kinetic energy. ${ }^{52}$ From the DPs, the normalized intensity ratios for $\mathrm{C} 1 / \mathrm{O}, \mathrm{Na} / \mathrm{O}$, and $\mathrm{Na} / \mathrm{C} 1$ ( $\mathrm{C} 1$ is the carboxyl peak; see Figure 1b) are calculated for four RH conditions (Figure 2). For all samples the $\mathrm{C} 1 / \mathrm{O}$ ratio is observed to be fairly stable with increasing depth (increasing $\mathrm{KE}$ ). Given the molar ratio of carbon to oxygen in the carboxyl group $(-\mathrm{COOH})$, in a homogeneous anhydrous sample, the $\mathrm{C} 1 / \mathrm{O}$ ratio is expected to be 0.5 . The lower observed $\mathrm{C} 1 / \mathrm{O}$ ratios (Figure 2a) may be due to the presence of additional oxygen in the adsorbed water even at low RH, which has been reported previously. ${ }^{33}$ At high $\mathrm{RH}$, the $\mathrm{C} 1 / \mathrm{O}$ ratios are also decreased $(0.5>\mathrm{C} 1 / \mathrm{O} \geq 0.15)$ due to dilution by condensed phase water.

In a homogeneous anhydrous sample, the expected molar ratios of $\mathrm{Na} / \mathrm{O}$ and $\mathrm{Na} / \mathrm{C} 1$ are 0.5 and 1.0 , respectively. Interestingly, a $\mathrm{Na}$ surface depletion is observed with respect to both $\mathrm{O}$ (Figure $2 \mathrm{~b}$ ) and $\mathrm{C1}$ (Figure 2c). This observation is potentially related to the sample preparation after introduction in the experimental cell, which includes a full cycle of deliquescence and efflorescence. Due to the nature of basic salts when the NaAc salt completely dissolves and dissociates upon deliquescence, a portion of the acetate ions recombine with protons from water to form neutral acetic acid (Figure 3). In solution, the molecular acetic acid has a larger surface propensity than acetate ions; ${ }^{50}$ thus, these molecules are enriched at the aqueous surface and consequently force the $\mathrm{CH}_{3} \mathrm{COO}^{-}$anions and $\mathrm{Na}^{+}$cations away from the surface. Such an enrichment has been previously found in liquid jet photoemission studies of acetic acid. ${ }^{50}$ The simplest explanation is that during subsequent efflorescence, when water molecules evaporate from the solution, the ions $\left(\mathrm{CH}_{3} \mathrm{COO}^{-}\right.$and $\left.\mathrm{Na}^{+}\right)$recombine and the salt precipitates, 

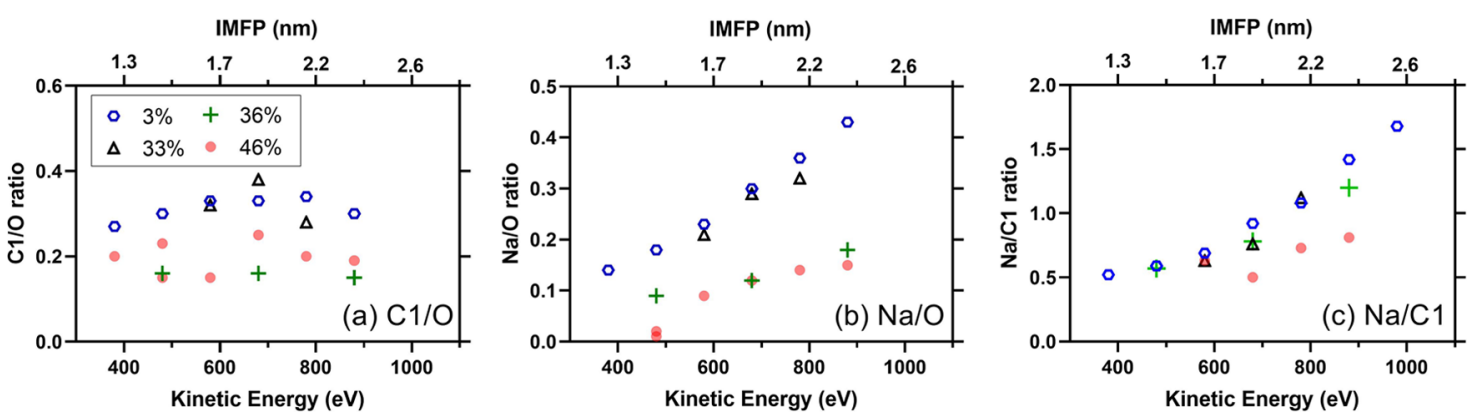

Figure 2. Depth profiles of the ratios (a) $\mathrm{C} 1 / \mathrm{O},(\mathrm{b}) \mathrm{Na} / \mathrm{O}$, and (c) $\mathrm{Na} / \mathrm{C} 1$, where $\mathrm{C} 1$ represents the acetate carboxyl component. Profiles were measured at four $\mathrm{RH}$ conditions, with $\mathrm{RH}=3 \%$ representing the dry salt, $\mathrm{RH}=33 \%$ representing the surface with physisorbed water, $\mathrm{RH}=36 \%$ representing the predeliquescence, and $\mathrm{RH}=46 \%$ representing the aqueous system. The raw data for the eight measured depth profiles can be found in Figure S2. The electron inelastic mean free path (IMFP) in sodium acetate is calculated by QUASES-IMFP-TPP2M Ver.3.0 and shown on the upper $x$-axis. ${ }^{53}$

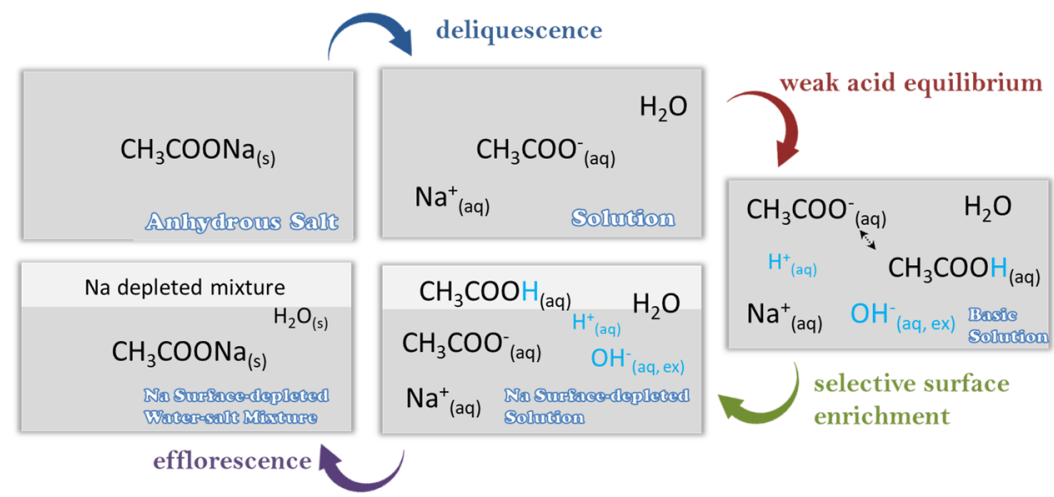

Figure 3. Illustration of the formation of a sodium-depleted salt surface during different stages of a deliquescence-efflorescence cycle.

but due to the spatial separation and surface properties some acetic acid (HAc) molecules are stabilized with water on the surface. The result is that the sodium is depleted from the surface relative to oxygen and carboxyl carbon (Figure $2 b, c)$. Balancing the molar ratios of molecular components via a stoichiometry calculation suggests that at the first point along the depth profile (IMFP $\approx 1.3 \mathrm{~nm}$ ) the surface contains a mixture of sodium acetate, acetic acid, and water, with the molar ratio of $\mathrm{NaAc} / \mathrm{HAc} / \mathrm{H}_{2} \mathrm{O}$ being 1:0.9:3.3 (details are found in the Supporting Information (SI)). There is no direct evidence for the precise chemical nature of the mixture but it may contain some low vapor pressure hydrates, which are also suggested by the NEXAFS features (Figure 4) detailed below. The mechanisms for forming the observed depletion and mixture are (i) the nature of the basic salt resulting in the formation of neutral acetic acid in the solution; (ii) the selective surface enhancement of these neutral molecules; and (iii) a potential kinetic barrier to re-homogenization due to spatial separation and special local conditions on the surface, resulting in varied local surface composition. In an atmospheric context, deliquescence-efflorescence cycles may occur many times, and this could lead to acidic and basic salt particles having such cation- or anion-depleted surfaces, though some factors (such as $\mathrm{pH}$ buffering in the atmosphere) may play critical roles in these processes.

Figure 2a,b also shows that subtle increases of $\mathrm{RH}$ around the DRH can substantially enhance water adsorption. The C1/ $\mathrm{O}$ and $\mathrm{Na} / \mathrm{O}$ ratios significantly decrease at $\mathrm{RH}=36 \%$ compared to their $\mathrm{RH}=33 \%$ values. At $\mathrm{RH}=36 \%$, the ratios (green pluses) are similar to those of bulk solution (red dots) when $\mathrm{RH}=46 \%(\mathrm{DRH} \leq 38 \%)$. Thus, already at $\mathrm{RH}=36 \%$
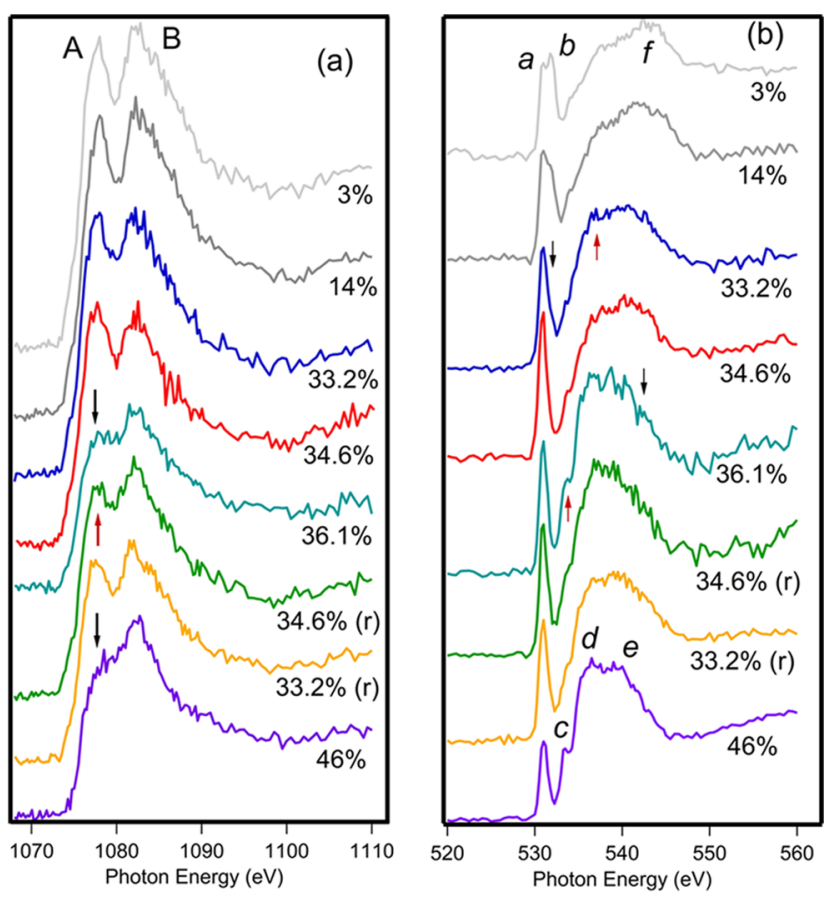

Figure 4. (a) Sodium K-edge and (b) oxygen K-edge NEXAFS at different RHs. The spectra are shown in the order that the individual experiments were carried out from top to bottom.

water adsorption must be significantly enhanced. In contrast, Figure $2 \mathrm{c}$ shows that the $\mathrm{Na} / \mathrm{C} 1$ ratio remains unchanged at $\mathrm{RH}=36 \%$ but changes when $\mathrm{RH}$ is increased to $46 \%$. In fact, 
Figure $2 \mathrm{c}$ illustrates that, relative to the expected unity molar ratio, $\mathrm{Na}$ is depleted at the surface for the full range of $\mathrm{RH}$. Interestingly, the subdeliquesced states also show a local $\mathrm{Na}$ enrichment just below the surface. This enrichment disappears when the system is fully solvated, and the ratio further from the surface tends toward the presumed bulk value of unity. Thus, the observations are consistent with the expectations of the Figure 3 model, which describes (1) the solvation of $\mathrm{NaAc}$ during deliquescence; (2) the recombination of molecular acetic acid in the aqueous phase; (3) the surface enhancement of molecular acetic acid in the aqueous phase; and (4) the formation of Na-depleted surface during efflorescence.

3.3. Reversible Changes of Local Physicochemical Environment at Subdeliquescence Conditions. Complementary NEXAFS measurements are consistent with the view of continuous water absorption from low $\mathrm{RH}$, but additionally demonstrate that the reversible water absorption includes the reversible solvation of the NaAc salt. In Figure 4, the sodium and oxygen K-edge NEXAFS spectra are plotted for a series of $\mathrm{RH}$, with the spectra arranged vertically in their chronological, experimental order to illustrate the system history. In the sodium K-edge NEXAFS spectra, a double-peak feature can be observed at around $1080 \mathrm{eV}$ photon energy (Figure 4a, peaks identified as A and B). These peaks are associated with sodium ions located in a disordered environment. ${ }^{54}$ As $\mathrm{RH}$ is increased within the experimental cell, the relative intensities of the A and $\mathrm{B}$ peaks change. In particular, when $\mathrm{RH}$ approaches $36.1 \%$, peak A decreases and flattens. Above $\mathrm{DRH}(\mathrm{RH}=46 \%$, purple curve), peak A flattens completely with respect to peak B, which indicates that peak $A$ is related to the sodium-carboxyl bond that breaks upon dissociation and solvation. Although the adsorbed water could attenuate the signal and flatten the sodium NEXAFS spectra to some extent, it would do so for both peaks. The similarities of the spectra at 36.1 and $46 \%$ suggest that the solvation shell of sodium at $36.1 \%$ is already well developed. It is also notable that the change of peak A in the subdeliquescence regime appears to be reversible, and when the RH is decreased from 36.1 to $34.6 \%$ (green line) peak A reappears. That is, the dissociated salt ions recombine to form the salt structure. The reversibility indicates that the sample has not fully deliquesced; thus, the DRH should be slightly higher than $\mathrm{RH}=36.1 \%$ and the ERH should be marginally higher than $26 \%$, referring to the gap between DRH and $\mathrm{ERH}$ at room temperature. ${ }^{33}$

In Figure $4 \mathrm{~b}$, the oxygen K-edge NEXAFS spectra are presented. At lower RHs ( $3 \%$ and 14\%) peaks a and b coexist at approximately $530 \mathrm{eV}$, but at higher $\mathrm{RH}$ peak $\mathrm{b}$ vanishes. This peak is likely related to hydrate-like components on the surface, and Figure S3 shows that this peak is very strong when the existence of hydrates is confirmed visually. Peak $c$ is indicative of free hydrogen and has previously been used as an indicator for liquid water layers on ice. ${ }^{40}$ Thus, here it can be used as a tracer for sorbed water on the NaAc surface. It is noted that even at $\mathrm{RH}=3 \%$ a minor peak $c$ is present, which is in line with previous findings that physisorbed water exists on the surface of salt at very low RHs. ${ }^{16,17,21,33,55}$ Similar to the sodium spectra, the oxygen spectra change dramatically at $\mathrm{RH}$ $=36.1 \%$, where the broad peak $f$ completely vanishes. Furthermore, peaks $\mathrm{d}$ and e emerge and can be linked to uncoordinated and tetrahedrally coordinated water molecules. ${ }^{56}$ In fact, at these highest RHs the spectral shape becomes very similar to that of acetate solutions. ${ }^{57}$
The simultaneous disappearance of peaks $f$ and $A$ implies that these are both related to the sodium-carboxyl bonds. The peak $f$ behavior with decreasing $\mathrm{RH}(36.1-34.6-33.2 \%)$ is also analogous to peak $\mathrm{A}$, where the peak re-emerges in the oxygen K-edge spectra (Figure $4 \mathrm{~b}$ ). Collectively, the spectra suggest that the sorbed water does not immediately initiate sodium solvation (peak $c$ in Figure $4 \mathrm{~b}$ ). Rather, enough water must be first present, as is the case at RH near the DRH, before $\mathrm{Na}$ begins to dissociate and dissolve. However, this appears to be a surface dissociation that remains reversible, likely until complete solvation occurs.

The potential differences between predeliquescence and reversibility in a nonequilibrated system must be carefully considered. In the latter case, for example, when the $\mathrm{RH}$ is only marginally higher than the $\mathrm{DRH}$, the deliquescence process may occur slowly due to limited water flux. Given enough time to overcome such a kinetic limitation, the entire bulk will completely deliquesce. If, however, within this time frame the $\mathrm{RH}$ dropped below the DRH the forcing would be reversed and the dissolving solution would begin to recrystallize because the presence of the existing crystal seeds would preclude the necessity of an activated efflorescence. In these experiments, measurements were made only after such evolutionary steps were completed and the system was observed to be in a steady state.

\section{CONCLUSIONS}

Here we employed APXPS to investigate the surface properties and processes of an atmospheric relevant carboxylic salt, sodium acetate, at subdeliquescence conditions. The depth profiles of the elemental ratios revealed that after experiencing a deliquescence-efflorescence cycle the salt surface becomes sodium-depleted. The mechanism causing the depletion includes (i) the formation of neutral acetic acid in the solution due to the nature of the basic salt, (ii) the selective surface enhancement of neutral molecules under aqueous condition, and (iii) a kinetic barrier to re-homogenization due to spatial separation and special local conditions on the surface, resulting in varied local surface composition. A stoichiometry calculation was carried out, and it suggested that at $\mathrm{RH}=3 \%$ the salt surface (IMFP $\approx 1.3 \mathrm{~nm}$ ) is equivalent to a mixture of sodium acetate, acetic acid, and water with a molar ratio of $1(\mathrm{NaAc}): 0.9(\mathrm{HAc}): 3.3\left(\mathrm{H}_{2} \mathrm{O}\right)$.

As $\mathrm{RH}$ gradually approached the deliquescence point, both reversible water uptake and reversible sodium solvation were confirmed by the NEXAFS spectra at the oxygen K-edge and the sodium K-edge, respectively. The solvation of sodium requires higher $\mathrm{RH}$ than that for water adsorption, which suggests that the water molecules were taken up onto the surface consistently but the solvation of salt surface would need sufficient water molecules to facilitate the process. In addition, as the surface was sodium-depleted, it required more adsorbed water to dissolve the surface first before reaching and dissociating the deeper sodium atoms.

\section{ASSOCIATED CONTENT}

\section{Supporting Information}

The Supporting Information is available free of charge at https://pubs.acs.org/doi/10.1021/acs.jpcc.0c00319.

Estimation of additional acetic acid and water; additional table on experimental conditions summary; and additional figures on the XPS spectrum of sodium acetate 
solution, NEXAFS of sodium acetate and sodium acetate trihydrate mixture, and all eight depth profiles measured (PDF)

\section{AUTHOR INFORMATION}

\section{Corresponding Authors}

Xiangrui Kong - Department of Chemistry and Molecular Biology, Atmospheric Science, University of Gothenburg, SE41296 Gothenburg, Sweden; (1) orcid.org/0000-0002-72050723; Email: kongx@chem.gu.se

Jan B. C. Pettersson - Department of Chemistry and Molecular Biology, Atmospheric Science, University of Gothenburg, SE41296 Gothenburg, Sweden; O orcid.org/0000-0001-84206126; Email: janp@chem.gu.se

\section{Authors}

Dimitri Castarède - Department of Chemistry and Molecular Biology, Atmospheric Science, University of Gothenburg, SE41296 Gothenburg, Sweden

Anthony Boucly - Laboratory of Environmental Chemistry, Paul Scherrer Institut, CH-5232 Villigen, Switzerland

Luca Artiglia - Laboratory of Environmental Chemistry, Paul Scherrer Institut, CH-5232 Villigen, Switzerland; 이이.org/ 0000-0003-4683-6447

Markus Ammann - Laboratory of Environmental Chemistry, Paul Scherrer Institut, CH-5232 Villigen, Switzerland; 구 orcid.org/0000-0001-5922-9000

Thorsten Bartels-Rausch - Laboratory of Environmental Chemistry, Paul Scherrer Institut, CH-5232 Villigen, Switzerland; orcid.org/0000-0002-7548-2572

Erik S. Thomson - Department of Chemistry and Molecular Biology, Atmospheric Science, University of Gothenburg, SE41296 Gothenburg, Sweden; 이이. orcid.0000-0003-24287539

Complete contact information is available at:

https://pubs.acs.org/10.1021/acs.jpcc.0c00319

\section{Notes}

The authors declare no competing financial interest.

\section{ACKNOWLEDGMENTS}

This work is supported by the Swedish Research Council VR (2015-04212, 2013-05153). X. K. acknowledges the supports from the National Natural Science Foundation of China (41975160). E.S.T. is also supported by the Swedish Research Council FORMAS and the Swedish Strategic Research Area MERGE.

\section{REFERENCES}

(1) Ravishankara, A. R. Heterogeneous and Multiphase Chemistry in the Troposphere. Science 1997, 276, 1058-1065.

(2) George, C.; Ammann, M.; D'Anna, B.; Donaldson, D. J.; Nizkorodov, S. A. Heterogeneous Photochemistry in the Atmosphere. Chem. Rev. 2015, 115, 4218-58.

(3) Huthwelker, T.; Ammann, M.; Peter, T. The Uptake of Acidic Gases on Ice. Chem. Rev. 2006, 106, 1375-1444.

(4) Abbatt, J. P. D.; et al. Halogen Activation Via Interactions with Environmental Ice and Snow in the Polar Lower Troposphere and Other Regions. Atmos. Chem. Phys. 2012, 12, 6237-6271.

(5) Simpson, W. R.; Brown, S. S.; Saiz-Lopez, A.; Thornton, J. A.; Glasow, R. Tropospheric Halogen Chemistry: Sources, Cycling, and Impacts. Chem. Rev. 2015, 115, 4035-62.
(6) Chen, H.; Nanayakkara, C. E.; Grassian, V. H. Titanium Dioxide Photocatalysis in Atmospheric Chemistry. Chem. Rev. 2012, 112, 5919-48.

(7) Nie, W.; et al. Polluted Dust Promotes New Particle Formation and Growth. Sci. Rep. 2015, 4, No. 6634.

(8) Burkholder, J. B.; Cox, R. A.; Ravishankara, A. R. Atmospheric Degradation of Ozone Depleting Substances, Their Substitutes, and Related Species. Chem. Rev. 2015, 115, 3704-59.

(9) Hoose, C.; Mohler, O. Heterogeneous Ice Nucleation on Atmospheric Aerosols: A Review of Results from Laboratory Experiments. Atmos. Chem. Phys. 2012, 12, 9817-9854.

(10) Kolb, C. E.; et al. An Overview of Current Issues in the Uptake of Atmospheric Trace Gases by Aerosols and Clouds. Atmos. Chem. Phys. 2010, 10, 10561-10605.

(11) Reid, J. P.; Bertram, A. K.; Topping, D. O.; Laskin, A.; Martin, S. T.; Petters, M. D.; Pope, F. D.; Rovelli, G. The Viscosity of Atmospherically Relevant Organic Particles. Nat. Commun. 2018, 9, No. 956.

(12) Artiglia, L.; et al. A Surface-Stabilized Ozonide Triggers Bromide Oxidation at the Aqueous Solution-Vapour Interface. Nat. Commun. 2017, 8, No. 700.

(13) McNeill, V. F.; Loerting, T.; Geiger, F. M.; Trout, B. L.; Molina, M. J. Hydrogen Chloride-Induced Surface Disordering on Ice. Proc. Natl. Acad. Sci. U.S.A. 2006, 103, 9422-7.

(14) Rossi, M. J. Heterogeneous Reactions on Salts. Chem. Rev. 2003, 103, 4823-4882.

(15) Kong, X. R.; Wolf, M. J.; Roesch, M.; Thomson, E. S.; BartelsRausch, T.; Alpert, P. A.; Ammann, M.; Prisle, N. L.; Cziczo, D. J. A Continuous Flow Diffusion Chamber Study of Sea Salt Particles Acting as Cloud Nuclei: Deliquescence and Ice Nucleation. Tellus B 2018, 70, No. 1463806.

(16) Verdaguer, A.; Sacha, G. M.; Luna, M.; Frank Ogletree, D.; Salmeron, M. Initial Stages of Water Adsorption on $\mathrm{NaCl}$ (100) Studied by Scanning Polarization Force Microscopy. J. Chem. Phys. 2005, 123.

(17) Peters, S. J.; Ewing, G. E. Thin Film Water on $\mathrm{NaCl}(100)$ under Ambient Conditions: An Infrared Study. Langmuir 1997, 13, 6345-6348.

(18) Ma, Q. X.; Liu, Y. C.; He, H. The Utilization of Physisorption Analyzer for Studying the Hygroscopic Properties of Atmospheric Relevant Particles. J. Phys. Chem. A 2010, 114, 4232-4237.

(19) Bruzewicz, D. A.; Checco, A.; Ocko, B. M.; Lewis, E. R.; McGraw, R. L.; Schwartz, S. E. Reversible Uptake of Water on $\mathrm{NaCl}$ Nanoparticles at Relative Humidity Below Deliquescence Point Observed by Noncontact Environmental Atomic Force Microscopy. J. Chem. Phys. 2011, 134, No. 044702.

(20) Wise, M. E.; Martin, S. T.; Russell, L. M.; Buseck, P. R. Water Uptake by Nacl Particles Prior to Deliquescence and the Phase Rule. Aerosol Sci. Technol. 2008, 42, 281-294.

(21) Zhang, Y. H.; Hu, Y. A.; Ding, F.; Zhao, L. J. FTIR-ATR Chamber for Observation of Efflorescence and Deliquescence Processes of $\mathrm{NaClO}_{4}$ Aerosol Particles on ZnSe Substrate. Chin. Sci. Bull. 2005, 50, 2149-2152.

(22) Wang, L. Y.; Ding, F.; Zhang, Y. H.; Zhao, L. J.; Hu, Y. A. Anomalous Hygroscopic Growth of Fine Particles of $\mathrm{MgSO}_{4}$ Aerosols Investigated by FTIR/ATR Spectroscopy. Spectrochim. Acta, Part A 2008, 71, 682-687.

(23) Castarède, D.; Thomson, E. S. A Thermodynamic Description for the Hygroscopic Growth of Atmospheric Aerosol Particles. Atmos. Chem. Phys. 2018, 18, 14939-14948.

(24) Dai, Q.; Hu, J.; Salmeron, M. Adsorption of Water on Nacl (100) Surfaces: Role of Atomic Steps. J. Phys. Chem. B 1997, 101, 1994-1998.

(25) Luna, M.; Rieutord, F.; Melman, N. A.; Dai, Q.; Salmeron, M. Adsorption of Water on Alkali Halide Surfaces Studied by Scanning Polarization Force Microscopy. J. Phys. Chem. A 1998, 102, 67936800. 
(26) Chebbi, A.; Carlier, P. Carboxylic Acids in the Troposphere, Occurrence, Sources, and Sinks: A Review. Atmos. Environ. 1996, 30, 4233-4249.

(27) Talbot, R. W.; Mosher, B. W.; Heikes, B. G.; Jacob, D. J.; Munger, J. W.; Daube, B. C.; Keene, W. C.; Maben, J. R.; Artz, R. S. Carboxylic Acids in the Rural Continental Atmosphere over the Eastern United States During the Shenandoah Cloud and Photochemistry Experiment. J. Geophys. Res.: Atmos. 1995, 100, 9335-9343.

(28) Kawamura, K.; Ng, L. L.; Kaplan, I. R. Determination of Organic Acids (C1 - C10) in the Atmosphere, Motor Exhausts, and Engine Oils. Environ. Sci. Technol. 1985, 19, 1082-1086.

(29) Kesselmeier, J.; Staudt, M. Biogenic Volatile Organic Compounds (Voc): An Overview on Emission, Physiology and Ecology. J. Atmos. Chem. 1999, 33, 23-88.

(30) Laskin, A.; Moffet, R. C.; Gilles, M. K.; Fast, J. D.; Zaveri, R. A.; Wang, B.; Nigge, P.; Shutthanandan, J. Tropospheric Chemistry of Internally Mixed Sea Salt and Organic Particles: Surprising Reactivity of $\mathrm{NaCl}$ with Weak Organic Acids. J. Geophys. Res.: Atmos. 2012, 117.

(31) Yao, X.; Zhang, L. Chemical Processes in Sea-Salt Chloride Depletion Observed at a Canadian Rural Coastal Site. Atmos. Environ. 2012, 46, 189-194.

(32) Wu, Z. J.; Nowak, A.; Poulain, L.; Hermann, H.; Wiedensohler, A. Hygroscopic Behavior of Atmospherically Relevant Water-Soluble Carboxylic Salts and Their Influence on the Water Uptake of Ammonium Sulfate. Atmos. Chem. Phys. 2011, 11, 1261712626.

(33) Peng, C.; Chan, C. K. The Water Cycles of Water-Soluble Organic Salts of Atmospheric Importance. Atmos. Environ. 2001, 35, $1183-1192$.

(34) Roberts, J. E. Temperature-Dependent Hygroscopic Properties of Atmospheric Carboxylic Acid Salt Aerosols Using ATR-FTIR Spectroscopy; University of Colorado, 2015; http://digital.auraria.edu/ AA00003767/00001.

(35) Velasco-Vélez, J. J.; et al. Atmospheric Pressure X-Ray Photoelectron Spectroscopy Apparatus: Bridging the Pressure Gap. Rev. Sci. Instrum. 2016, 87, No. 053121.

(36) Orlando, F.; et al. The Environmental Photochemistry of Oxide Surfaces and the Nature of Frozen Salt Solutions: A New in Situ XPS Approach. Top. Catal. 2016, 59, 591-604.

(37) Roy, K.; Artiglia, L.; van Bokhoven, J. A. Ambient Pressure Photoelectron Spectroscopy: Opportunities in Catalysis from Solids to Liquids and Introducing Time Resolution. ChemCatChem 2018, 10, 666-682.

(38) Karslıŏglu, O.; Bluhm, H. Ambient-Pressure X-Ray Photoelectron Spectroscopy (APXPS); Springer, 2017; Vol. 114.

(39) Starr, D. E.; Liu, Z.; Hävecker, M.; Knop-Gericke, A.; Bluhm, $\mathrm{H}$. Investigation of Solid/Vapor Interfaces Using Ambient Pressure XRay Photoelectron Spectroscopy. Chem. Soc. Rev. 2013, 42, 58335857.

(40) Bluhm, H.; Ogletree, D. F.; Fadley, C. S.; Hussain, Z.; Salmeron, N. The Premelting of Ice Studied with Photoelectron Spectroscopy. J. Phys. Condens. Mater. 2002, 14, L227-L233.

(41) Kong, X.; Waldner, A.; Orlando, F.; Artiglia, L.; Huthwelker, T.; Ammann, M.; Bartels-Rausch, T. Coexistence of Physisorbed and Solvated $\mathrm{HCl}$ at Warm Ice Surfaces. J. Phys. Chem. Lett. 2017, 8, $4757-4762$

(42) Bartels-Rausch, T.; Orlando, F.; Kong, X.; Artiglia, L.; Ammann, M. Experimental Evidence for the Formation of Solvation Shells by Soluble Species at a Nonuniform Air-Ice Interface. ACS Earth Space Chem. 2017, 1, 572-579.

(43) Křepelová, A.; Bartels-Rausch, T.; Brown, M. A.; Bluhm, H.; Ammann, M. Adsorption of Acetic Acid on Ice Studied by AmbientPressure XPS and Partial-Electron-Yield NEXAFS Spectroscopy at 230-240 K. J. Phys. Chem. A 2013, 117, 401-9.

(44) Waldner, A.; Artiglia, L.; Kong, X.; Orlando, F.; Huthwelker, T.; Ammann, M.; Bartels-Rausch, T. Pre-Melting and the Adsorption of Formic Acid at the Air-Ice Interface at $253 \mathrm{~K}$ as Seen by NEXAFS and XPS. Phys. Chem. Chem. Phys. 2018, 20, 24408-24417.
(45) Starr, D. E.; Pan, D.; Newberg, J. T.; Ammann, M.; Wang, E. G.; Michaelides, A.; Bluhm, H. Acetone Adsorption on Ice Investigated by X-Ray Spectroscopy and Density Functional Theory. Phys. Chem. Chem. Phys. 2011, 13, 19988-96.

(46) Newberg, J. T.; Bluhm, H. Adsorption of 2-Propanol on Ice Probed by Ambient Pressure X-Ray Photoelectron Spectroscopy. Phys. Chem. Chem. Phys. 2015, 17, 23554-8.

(47) Křepelová, A.; Newberg, J. T.; Huthwelker, T.; Bluhm, H.; Ammann, M. The Nature of Nitrate at the Ice Surface Studied by XPS and NEXAFS. Phys. Chem. Chem. Phys. 2010, 12, 8870-8880.

(48) Ghosal, S.; Hemminger, J. C.; Bluhm, H.; Mun, B. S.; Hebenstreit, E. L.; Ketteler, G.; Ogletree, D. F.; Requejo, F. G.; Salmeron, M. Electron Spectroscopy of Aqueous Solution Interfaces Reveals Surface Enhancement of Halides. Science 2005, 307, 563-6.

(49) Křepelová, A.; Huthwelker, T.; Bluhm, H.; Ammann, M. Surface Chemical Properties of Eutectic and Frozen Nacl Solutions Probed by XPS and NEXAFS. ChemPhysChem 2010, 11, 3859-66.

(50) Ottosson, N.; Wernersson, E.; Soderstrom, J.; Pokapanich, W.; Kaufmann, S.; Svensson, S.; Persson, I.; Ohrwall, G.; Bjorneholm, O. The Protonation State of Small Carboxylic Acids at the Water Surface from Photoelectron Spectroscopy. Phys. Chem. Chem. Phys. 2011, 13, 12261-12267.

(51) Ketteler, G.; Ashby, P.; Mun, B. S.; Ratera, I.; Bluhm, H.; Kasemo, B.; Salmeron, M. In Situphotoelectron Spectroscopy Study of Water Adsorption on Model Biomaterial Surfaces. J. Phys.: Condens. Matter 2008, 20, No. 184024.

(52) NIST. NIST Standard Reference Database; National Institute of Standards and Technology: Gaithersburg, 2016; Vol. 69.

(53) Tanuma, S.; Powell, C. J.; Penn, D. R. Calculations of Electron Inelastic Mean Free Paths. V. Data for 14 Organic Compounds over the 50-2000 eV Range. Surf. Interface Anal. 1994, 21, 165-176.

(54) De Wispelaere, S.; Cabaret, D.; Levelut, C.; Rossano, S.; Flank, A.-M.; Parent, P.; Farges, F. Na-, Al-, and Si K-Edge XANES Study of Sodium Silicate and Sodium Aluminosilicate Glasses: Influence of the Glass Surface. Chem. Geol. 2004, 213, 63-70.

(55) Ewing, G. E. $\mathrm{H}_{2} \mathrm{O}$ on NaCl: From Single Molecule, to Clusters, to Monolayer, to Thin Film, to Deliquescence, In Intermolecular Forces and Clusters II, Wales, D. J.2005; Vol 116, pp 1-25.

(56) Wernet, P.; et al. The Structure of the First Coordination Shell in Liquid Water. Science 2004, 304, 995-999.

(57) Petit, T.; Lange, K. M.; Conrad, G.; Yamamoto, K.; Schwanke, C.; Hodeck, K. F.; Dantz, M.; Brandenburg, T.; Suljoti, E.; Aziz, E. F. Probing Ion-Specific Effects on Aqueous Acetate Solutions: Ion Pairing Versus Water Structure Modifications. Struct. Dyn. 2014, 1, No. 034901. 